\title{
Insulin Secretion and Risk for Future Diabetes in Subjects with a Nonpositive Insulinogenic Index
}

\author{
Daisuke Aono, ${ }^{1}$ Rie Oka $\left(\mathbb{D},{ }^{1,2}\right.$ Mitsuhiro Kometani, ${ }^{1}$ Yoshimichi Takeda, ${ }^{1}$ \\ Shigehiro Karashima, ${ }^{1}$ Kenichi Yoshimura, ${ }^{3}$ Yoshiyu Takeda, ${ }^{1}$ and Takashi Yoneda ${ }^{1}$ \\ ${ }^{1}$ Department of Cardiovascular and Internal Medicine, Kanazawa University Graduate School of Medicine, Kanazawa, Japan \\ ${ }^{2}$ Department of Internal Medicine, Hokuriku Central Hospital, Oyabe, Japan \\ ${ }^{3}$ Department of Biostatistics, Innovative Clinical Research Center (iCREK), Kanazawa University Hospital, Kanazawa, Japan
}

Correspondence should be addressed to Rie Oka; ririoka@goo.jp

Received 5 October 2017; Accepted 22 January 2018; Published 22 March 2018

Academic Editor: Janet H. Southerland

Copyright ( 2018 Daisuke Aono et al. This is an open access article distributed under the Creative Commons Attribution License, which permits unrestricted use, distribution, and reproduction in any medium, provided the original work is properly cited.

\begin{abstract}
Aim. To characterize subjects with a nonpositive insulinogenic index and longitudinally observe changes in their glucose tolerance. Subjects and Methods. A historical cohort study was conducted using data from the medical checkups of public school workers. Indices of insulin secretion and insulin sensitivity derived from oral glucose tolerance test (OGTT) and the incidences of diabetes and impaired glucose tolerance (IGT) were compared among subgroups of subjects with different insulinogenic index (change in insulin/change in glucose over the first $30 \mathrm{~min}$ on the OGTT). Results. Of the 1464 nondiabetic subjects at baseline, $72(4.9 \%)$ subjects had a nonpositive insulinogenic index: 42 of those subjects had a nonpositive glucose response $\left(\Delta \mathrm{Glu}_{0-30} \leq 0\right)$ and 30 had a nonpositive insulin response $\left(\Delta \operatorname{Ins}_{0-30} \leq 0\right)$. Compared with subjects who had normal glucose tolerance (NGT) with insulinogenic index $\geq 0.4$, subjects with a nonpositive glucose response had a higher first-phase Stumvoll and lower incidences of diabetes and IGT based on a log-rank test $(p<0.05)$, whereas subjects with a nonpositive insulin response had lower indices of insulin secretion and a higher incidence of diabetes $(p<0.05)$. Conclusions. These results demonstrate that in the first $30 \mathrm{~min}$ on the OGTT, subjects with a nonpositive insulinogenic index due to a nonpositive glucose response $\left(\Delta \mathrm{Glu}_{0-30} \leq 0\right)$ had a lower risk for future diabetes and that subjects with nonpositive insulin response $\left(\Delta \operatorname{Ins}_{0-30} \leq 0\right)$ had a higher risk for future one.
\end{abstract}

\section{Introduction}

Insulinogenic index (change in insulin/change in glucose over the first $30 \mathrm{~min}$ after the load) on the oral glucose tolerance test (OGTT) has been widely used as an index of early phase insulin secretion in clinical studies [1-4]. It is highly correlated with the acute insulin response (AIR) on intravenous glucose tolerance test (IVGTT) and is considered a reasonable surrogate $[5,6]$. Measuring insulinogenic index has several advantages; it involves less complex protocols, needs less costs, and utilizes a physiological route of glucose administration $[7,8]$. Simpler methods for the assessment of insulin secretion are those based on basal glucose and insulin concentrations, such as HOMA-beta [9], but fasting levels cannot provide insight into the secretory response of beta cells to rising glucose concentrations [8]. Indeed, insulinogenic index or its composite with insulin sensitivity (oral disposition index) has been demonstrated to be predictive of type 2 diabetes, independent of fasting plasma glucose in different populations [4, 10-12].

Sometimes, however, a small number of subjects in general populations exhibit a nonpositive insulinogenic index due to either a decrement in insulin or in glucose value $30 \mathrm{~min}$ after glucose ingestion from fasted states [13]. Most studies, including ours, exclude them from the main analysis [14]. Abdul-Ghani et al. have reported a lower risk for future diabetes in individuals whose plasma glucose concentrations returned to equal to or below fasting levels within $30 \mathrm{~min}$ compared with those who required longer time to return their plasma glucose to fasting levels [15]. Besides the report 
by Abdul-Ghani et al., there has been no report on the clinical characteristics and the risk for future diabetes in subjects with a nonpositive insulinogenic index.

The aim of this study, therefore, was to characterize subjects with a nonpositive insulinogenic index and longitudinally observe changes in their glucose tolerance.

\section{Methods}

2.1. Study Participants. A historical cohort study was conducted using data from the medical checkups of public school employees collected at Hokuriku Central Hospital [14]. During April 2006 and March 2010 (baseline period), 2340 employees underwent an OGTT at a medical checkup [16]. If employees received more than one checkup during the baseline period, the initial checkup data were used. After those who had fasting plasma glucose $\geq 126 \mathrm{mg} / \mathrm{dL}$ and/or $2 \mathrm{~h}$ plasma glucose $\geq 200 \mathrm{mg} / \mathrm{dL}(n=85)$, those who had HbA1c values $\geq 6.9 \%(52 \mathrm{mmol} / \mathrm{mol})(n=42)$, those who had undergone gastrectomy $(n=32)$, those who were taking steroids $(n=1)$ or anticancer drugs $(n=1)$, those who or had any missing data $(n=18)$ were excluded, 2161 nondiabetic individuals were selected. Of these, 1464 individuals repeated checkups at least once until March 2016 and comprised our study sample. The remaining 697 participants did not have a repeat checkup, yielding a follow-up rate of $67.7 \%$. If the subjects developed diabetes, the follow-up ended at that time. An OGTT was performed at all checkups during the followup period; however, within the last two years (April 2014 to March 2016), an OGTT was performed on 1191 participants and the measurement of fasting plasma glucose only was performed in the remaining 273 participants for financial reasons. Information on smoking and drinking habits and a medical history were obtained via a questionnaire. Participants were considered current smokers if they smoked at least one cigarette per day. Alcohol use was defined by the number of days per week it was consumed, regardless of the amount. Informed consent was obtained by an opt-out method, and the institutional review board of the Kanazawa University approved the study protocol on June 21, 2017 (IRB number 2497-1); the study protocol conforms to the provisions of the Declaration of Helsinki. The study was registered on the University Hospital Medical Information Network Clinical Trials Registry (UMIN-CTR, http://www. umin.ac.jp/ctr, UMIN ID: UMIN000017662).

2.2. Blood Sampling and Assay. All evaluations were performed at the Health Check Department of the Hokuriku Central Hospital. Participants were asked to visit the hospital between 8:00 a.m. and 9:00 a.m. after an overnight fast. At the baseline visit, an OGTT (75 g dextrose monohydrate in $250 \mathrm{~mL}$ water) with $0,30,60$, and $120 \mathrm{~min}$ sampling to determine plasma glucose and insulin concentrations was performed on all participants [16]. Plasma glucose was assessed using the glucose oxidase method (Automatic Glucose Analyzer ADAMS Glucose GA-1160, Arkray, Kyoto, Japan) at the hospital laboratory. Insulin concentration assays were performed by the chemiluminescence immunoassay method at a commercial laboratory (BML Inc., Tokyo,
Japan), with an intra-assay coefficient of variation (CV) of $2.4-3.2 \%$ based on 10 replicates of 3 different samples. Height and weight were measured, and body mass index (BMI) was calculated by dividing weight $(\mathrm{kg})$ by height squared $\left(\mathrm{m}^{2}\right)$.

2.3. Calculations of Indices of Insulin Secretion and Insulin Sensitivity. The indices of insulin secretion used in this study were as follows: insulinogenic index $=\left(\mathrm{Ins}_{30}-\mathrm{Ins}_{0}\right)$ / $\left(\mathrm{Gluc}_{30}-\mathrm{Gluc}_{0}\right)$ or $\Delta \mathrm{Ins}_{0-30} / \Delta \mathrm{Glu}_{0-30}$, where Ins ${ }_{y}$ and $\mathrm{Glu}_{y}$ represent values at time $(y: \min )$ during the OGTT $[5,6]$; the ratio of area under the curve (AUC) for insulin to AUC for glucose for the specific time frame, which was calculated by applying the trapezoid rule; first-phase Stumvoll $=1283+1.829 \times \mathrm{Ins}_{30}-138.7 \times \mathrm{Glu}_{30}+3.772 \times \mathrm{Ins}_{0} ; \quad$ and second-phase Stumvoll $=286+0.416 \times \mathrm{Ins}_{30}-25.94 \times \mathrm{Glu}_{30}+$ $0.926 \times \mathrm{Ins}_{0}$ [17]. The indices of insulin sensitivity were as follows: Matsuda insulin sensitivity index $($ ISI $)=10,000$ / $\left(\mathrm{Glu}_{0} \times \mathrm{Ins}_{0} \times \mathrm{Glu}_{120} \times \mathrm{Ins}_{120}\right)^{0.5}[18]$ and homeostatic model assessment of insulin resistance $(\mathrm{HOMA}-\mathrm{IR})=\mathrm{Glu}_{0} \times \mathrm{Ins}_{0} /$ 405 [9]. We used different units for glucose concentration and insulin concentration in calculating each index, as described in Table 1.

2.4. Statistical Analysis. The data are presented as the mean \pm standard deviation or median with interquartile ranges for continuous variables or as a frequency for categorical variables. Continuous variables were compared using one-way analysis of variance (ANOVA) or Kruskal-Wallis test, and categorical values were compared using a $\chi^{2}$ test, with a Bonferroni correction for multiple comparisons. The participants were classified by their insulinogenic index at 0.4 because this threshold was adopted by the Japan Diabetes Society to identify individuals at a high risk of progression to diabetes [19]. Participants were further classified by their glucose tolerance using the criteria of the American Diabetes Association (ADA) [20]; subjects were categorized as having NGT (fasting plasma glucose $<100 \mathrm{mg} / \mathrm{dL}$ and $2 \mathrm{~h}$ plasma glucose $<$ $140 \mathrm{mg} / \mathrm{dL}$ ), impaired fasting glucose (IFG) (fasting plasma glucose $=100-125 \mathrm{mg} / \mathrm{dL}$ ), and impaired glucose tolerance (IGT) (2-hour plasma glucose $=140-199 \mathrm{mg} / \mathrm{dL}$ ). Among groups, indices of insulin sensitivity and insulin secretion were compared using analysis of covariance (ANCOVA) with age, gender, and BMI as covariates. Insulinogenic index and HOMA-IR were log-transformed using the natural log prior to analysis to reduce skewness; the transformed values produced a good fit to normal distribution. Finally, the progression to diabetes defined as fasting plasma glucose $\geq$ $126 \mathrm{mg} / \mathrm{dL}, 2$-hour plasma glucose $\geq 200 \mathrm{mg} / \mathrm{dL}$, and/or taking treatments for diabetes or to IGT among subjects grouped by insulinogenic index was compared by the Kaplan-Meier method. The analysis of the progression to IGT was performed in 982 out of the 1169 NGT subjects at baseline, because the remaining 187 NGT subjects did not receive an OGTT at follow-up. A $p$ value of $<0.05$ was considered statistically significant. All analyses were conducted using SPSS software version 24.0 for Windows (SPSS Inc., Chicago, USA). 


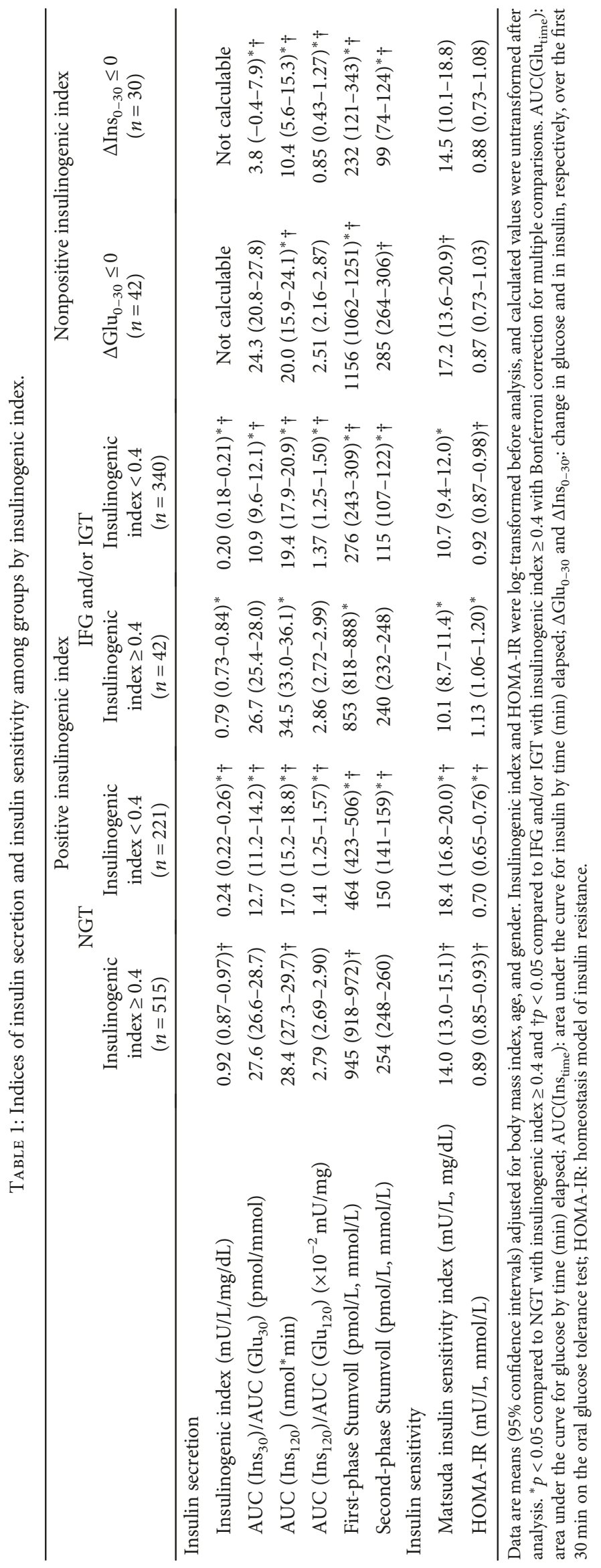




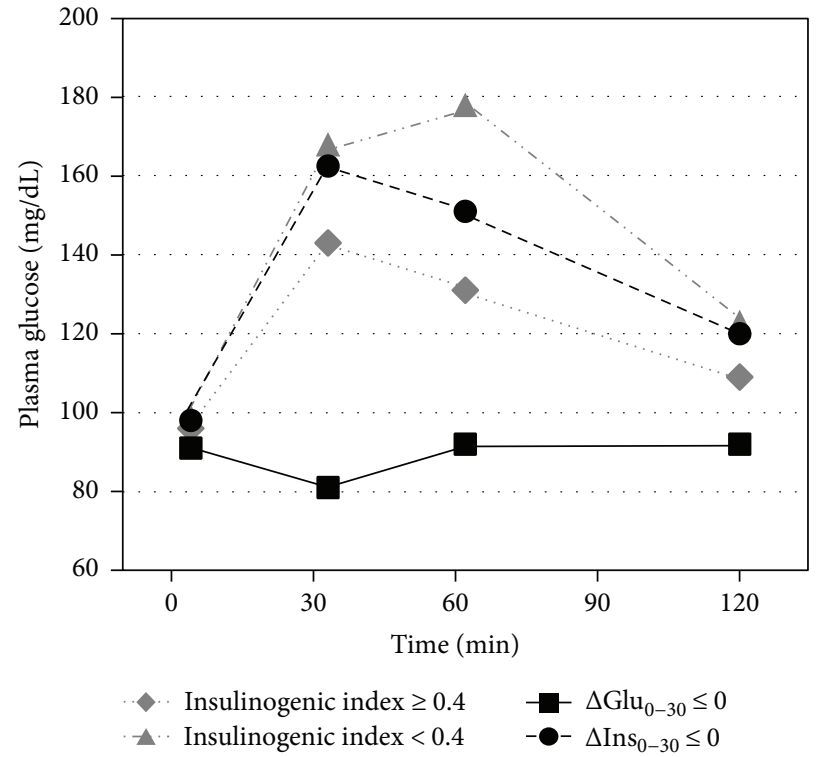

(a)

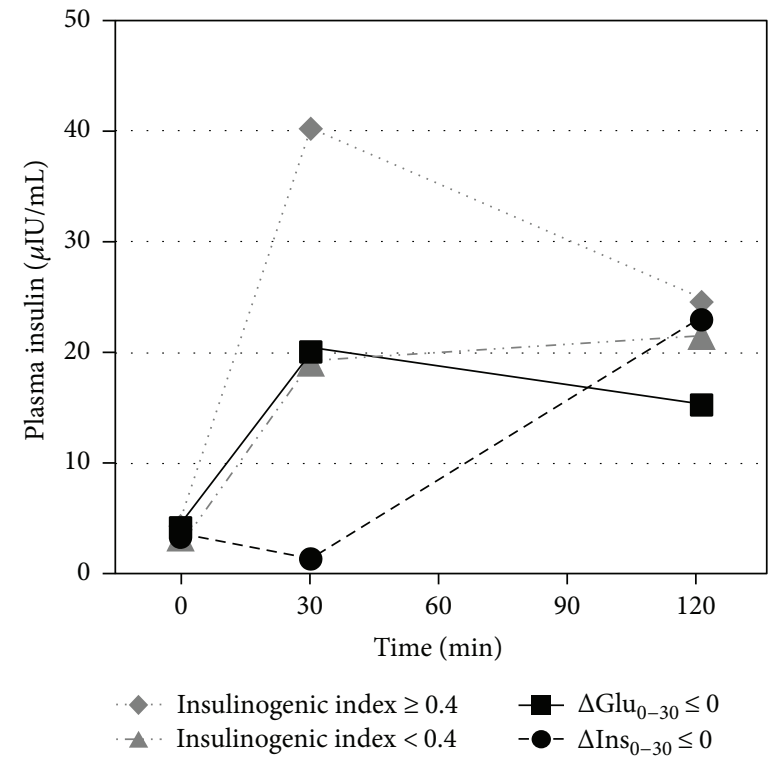

(b)

FIGURE 1: Plasma glucose and insulin concentrations on the OGTT among subgroups of subjects with a different insulinogenic index as presented as median values.

\section{Results}

Study subjects were 1464 nondiabetic individuals with a mean age of 52.0 years and a mean BMI of $23.9 \mathrm{~kg} / \mathrm{m}^{2}$ at baseline. There were $42(2.9 \%)$ subjects whose plasma glucose concentrations fell equal to or below their fasting levels at $30 \mathrm{~min}\left(\Delta \mathrm{Glu}_{0-30} \leq 0\right)$ and $30(2.0 \%)$ subjects whose insulin concentrations fell equal to or below the fasting levels at $30 \mathrm{~min}$ after the oral glucose load $\left(\Delta \mathrm{Ins}_{0-30} \leq 0\right)$. Three subjects with double nonpositive values, resulting in a positive insulinogenic index, were excluded from the following analysis. As shown in Figure 1, subjects with $\Delta \operatorname{Ins}_{0-30} \leq 0$ increased their insulin concentrations at $120 \mathrm{~min}$ from $30 \mathrm{~min}$, while those with $\Delta \mathrm{Glu}_{0-30} \leq 0$ got to return their insulin concentrations at $120 \mathrm{~min}$. As shown in Table 2, subjects with $\Delta \mathrm{Glu}_{0-30} \leq 0$ included a lower proportion of men and had a lower BMI and lower glucose and insulin concentrations during OGTT, compared with subjects with insulinogenic index $\geq 0.4 \quad(p<0.05)$. Subjects with $\Delta \operatorname{Ins}_{0-30} \leq 0$ had a higher BMI and higher glucose and fasting insulin concentrations compared with subjects with $\Delta \mathrm{Glu}_{0-30} \leq 0$ $(p<0.05)$. Subjects with $\Delta \mathrm{Glu}_{0-30} \leq 0$ had a significantly higher proportion of NGT (92.9\%) compared with the other three groups listed in Table $2(p<0.05)$.

To evaluate insulin secretion and insulin sensitivity on the basis of the OGTT, we classified subjects with nonpositive insulinogenic index into 2 groups (i.e., $\Delta \mathrm{Glu}_{0-30} \leq 0$ and $\left.\Delta \mathrm{Ins}_{0-30} \leq 0\right)$ and those with positive insulinogenic index into 2 groups as well [with subgroups] (i.e., NGT [insulinogenic index $\geq 0.4$ or $<0.4$ ] and IFG and/or IGT [insulinogenic index $\geq 0.4$ or $<0.4]$ ) (Table 1 ). In subjects with $\Delta \mathrm{Glu}_{0-30} \leq 0$, indices of insulin secretion such as AUC $\left(\operatorname{Ins}_{30}\right) / A U C\left(\mathrm{Glu}_{30}\right)$ and $\mathrm{AUC}\left(\mathrm{Ins}_{120}\right) / \mathrm{AUC}\left(\mathrm{Glu}_{120}\right)$ were not significantly decreased and first-phase Stumvoll was increased compared with NGT with insulinogenic index $\geq 0.4$. In subjects with $\Delta \mathrm{Ins}_{0-30} \leq 0$, all indices of insulin secretion examined were significantly decreased compared with IFG and/or IGT as well as NGT with insulinogenic index $\geq 0.4$. Matsuda ISI and HOMA-IR were not significantly different in subgroups with nonpositive insulinogenic index compared with NGT with insulinogenic index $\geq 0.4$. These indices were estimated after adjustments for gender, age, and BMI; however, the results were essentially the same before the adjustments (data not shown).

The progression to diabetes (Figure 2) or to IGT (Figure 3) was assessed among different subgroups by insulinogenic index. In subjects with $\Delta \mathrm{Glu}_{0-30} \leq 0$, there was no progression to diabetes nor to IGT during a mean follow-up period of 5.6 years, which was significantly less than NGT with insulinogenic index $\geq 0.4$ by log-rank test $(p<0.05)$. In subjects with $\Delta$ Ins $_{0-30} \leq 0$, the incidence of diabetes was significantly higher compared with NGT with insulinogenic index $\geq 0.4(P<0.05)$ while that of IGT was not statistically different by log-rank test. In comparison between subjects with $\Delta \mathrm{Glu}_{0-30} \leq 0$ and those with $\Delta$ Ins $_{0-30} \leq 0$, the incidences of diabetes and of IGT were significantly different $(p=0.016$ and $p<0.001$, resp.).

\section{Discussion}

In this study, subjects with a nonpositive insulinogenic index were characterized based on insulin secretion and insulin sensitivity and diabetes and IGT incidences were compared with subjects who had a positive insulinogenic index. Although the prevalence of nonpositive insulinogenic index was low in agreement with prior studies investigating Western cohorts [13], this is the first study in Asian populations that longitudinally observed the future incidence of glucose intolerance in subjects with a nonpositive insulinogenic index. The findings of the current study could be useful for 
TABLE 2: Baseline characteristics by level of the insulinogenic index.

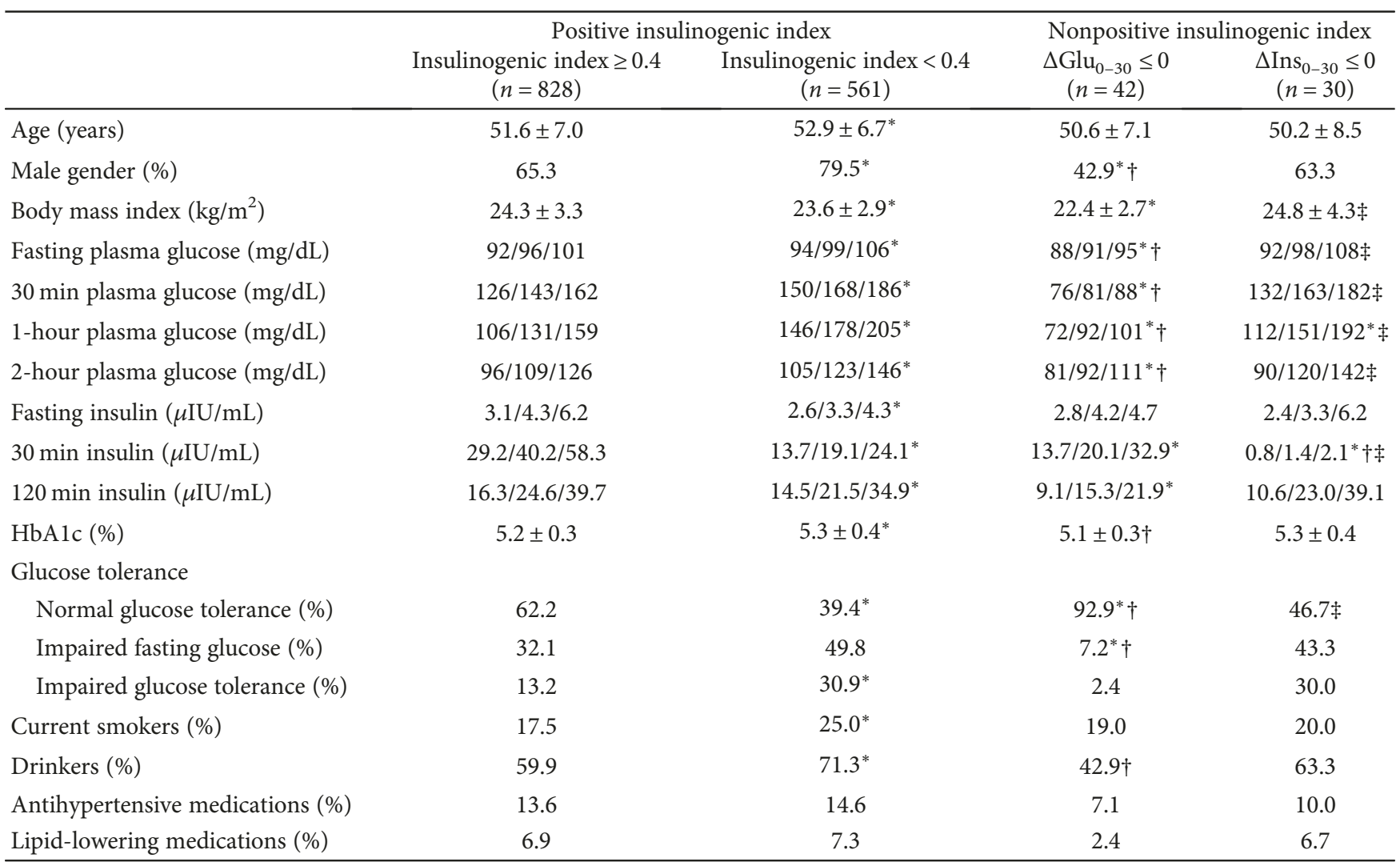

Data are expressed as mean \pm standard deviation, 25/50/75th percentile values, or $\%$. Characteristics among groups were compared using one-way ANOVA for continuous variables and chi-square tests for categorical variables with Bonferroni correction for multiple comparisons. ${ }^{*} p<0.05$ compared to insulinogenic index $\geq 0.4, \dagger p<0.05$ compared to insulinogenic index $<0.4$, $\$ p<0.05$ compared to $\Delta \mathrm{Glu}_{0-30} \leq 0 . \Delta \mathrm{Glu}_{0-30}$ and $\Delta \mathrm{Ins}_{0-30}$, change in glucose and in insulin, respectively, over the first $30 \mathrm{~min}$ on the oral glucose tolerance test.

estimating the risk for diabetes when clinicians encounter subjects with a nonpositive insulinogenic index.

The prevalence of a nonpositive insulinogenic index was $4.9 \%(72 / 1464)$ in nondiabetic subjects in this study. The prevalence in other cohorts has been reported as $8.2 \%$ in the San Antonio Heart Study, 3.4\% in the Genetics of NIDDM Study, and 2.5\% in the Japanese American Community Diabetes Study [13]. There were two reasons for a nonpositive insulinogenic index: a nonpositive glucose response $\left(\Delta \mathrm{Glu}_{0-30} \leq 0\right)$ and a nonpositive insulin response $\left(\Delta \operatorname{Ins}_{0-30} \leq 0\right)$ after a glucose load. The former included a higher proportion of NGT than the latter in this study (92.9\% versus $46.7 \%)$, which is in agreement with the results from the San Antonio Heart Study (81.4\% versus $11.8 \%)$. We confirmed and extended the observation that a nonpositive insulinogenic index occurs at a given frequency in Japanese populations.

Subjects with a nonpositive glucose response $30 \mathrm{~min}$ after a glucose load had similar or even higher insulin secretion compared with NGT with insulinogenic index $\geq 0.4$ and a lower risk for future deterioration of glucose tolerance. Abdul-Ghani et al. have reported that individuals whose plasma glucose concentrations return to equal to or below the fasting levels by $30 \mathrm{~min}$ after a glucose load showed the highest insulin sensitivity, the highest insulin secretion, and the lowest risk for future diabetes, compared with those who required $>30 \mathrm{~min}$ for their plasma glucose to return to fasting levels in Mexican Americans [15] and Caucasians [21]. Of note, the insulinogenic index could not be calculated due to nonpositive glucose response in their study, so they assessed insulin secretion by AUC $\left(\operatorname{Ins}_{30}\right) / \mathrm{AUC}\left(\mathrm{Glu}_{30}\right)$, which was also applied in this study. The subjects with a nonpositive glucose response are likely to be highly efficient in disposing glucose and in maintaining normal glucose homeostasis following a glucose load.

Subjects with a nonpositive insulin response $30 \mathrm{~min}$ after the glucose load had the lowest insulin secretion among different groups of the insulinogenic index. This group comprised of more IFG and/or IGT and showed a higher BMI compared with the abovementioned subjects with a nonpositive glucose response. In the study examining the acute (first-phase) insulin response to intravenous glucose, a paradoxically nonpositive insulin response had also been observed in subjects with fasting hyperglycemia [22]. A nonpositive insulin response at $30 \mathrm{~min}$ on the OGTT may reflect an impairment of early insulin response, which is one of the primary pathophysiologic changes of type 2 diabetes.

Of note, insulin levels at $120 \mathrm{~min}$ in subjects with a nonpositive insulin response were similar to other groups, 


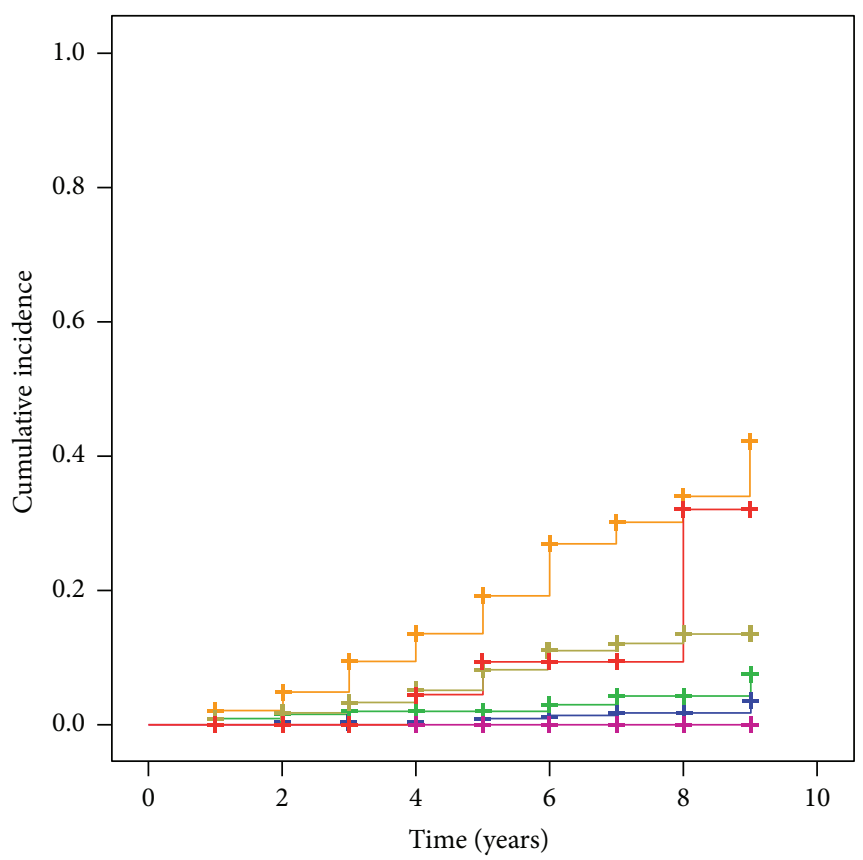

\begin{tabular}{|c|c|c|c|c|c|c|}
\hline & \multicolumn{4}{|c|}{ Positive insulinogenic index } & \multicolumn{2}{|c|}{ Nonpositive insulinogenic index } \\
\hline & \multicolumn{2}{|c|}{ NGT } & \multicolumn{2}{|c|}{ IFG and/or IGT } & \multirow{2}{*}{$\begin{array}{c}\Delta \mathrm{Glu}_{0-30} \leq 0 \\
(n=42)\end{array}$} & \multirow{2}{*}{$\begin{array}{c}\Delta \operatorname{Ins}_{0-30} \leq 0 \\
(n=30)\end{array}$} \\
\hline & $\begin{array}{l}\text { Insulinogenic } \\
\text { index }\end{array}$ & $\begin{array}{l}\text { Insulinogenic } \\
\text { index }\end{array}$ & $\begin{array}{l}\text { Insulinogenic } \\
\text { index }\end{array}$ & $\begin{array}{l}\text { Insulinogenic } \\
\text { index }\end{array}$ & & \\
\hline & $\geq 0.4(n=515)$ & $<0.4(n=221)$ & $\geq 0.4(n=313)$ & $<0.4(n=340)$ & & \\
\hline Incidence (\%) & $6(1.2)$ & $7(3.2)$ & $25(8.0) *$ & $69(20.3) *$ & $0^{*}$ & $4(13.3) * \#$ \\
\hline $\begin{array}{l}\text { Mean follow-up time } \\
\text { (years) }\end{array}$ & 5.4 & 5.2 & 4.9 & 4.6 & 5.6 & 4.7 \\
\hline $\begin{array}{l}\text { Incidence rate } \\
\text { (per } 100 \text { person-years) }\end{array}$ & 0.2 & 0.6 & 1.6 & $4.4^{*}$ & $0.0^{*}$ & $2.8^{* \#}$ \\
\hline
\end{tabular}

*Significantly different from NGT with insulinogenic index $\geq 0.4$ by log-rank test $(p<0.001)$. ${ }^{\#}$ Significantly different between $\Delta \mathrm{Glu}_{0-30} \leq 0$ and $\Delta \operatorname{Ins}_{0-30} \leq 0(P=0.016)$.

FIgure 2: Cumulative incidence of diabetes by the Kaplan-Meier method among groups by insulinogenic index.

indicating that insulin secretion was delayed but preserved (Figure 1). Recently, Lorenzo et al. have reported that indices of insulin secretion derived from the late OGTT period as well as the early period (e.g., insulinogenic index) independently predict the incidence of diabetes from the San Antonio Study [23]. Although the late insulin secretion may keep the subjects with a nonpositive insulin response from the development of diabetes, they are likely to have a higher risk of diabetes compared with the IFG and/or IGT with insulinogenic index $\geq 0.4$.

We evaluated several OGTT-based indices of insulin secretion. When glucose is administered intravenously, the insulin response to a hyperglycemic stimulation is biphasic [24]; plasma insulin concentrations increase rapidly to a peak at 2 to $4 \mathrm{~min}$, decrease within 10 to $15 \mathrm{~min}$ (first-phase insulin release), and gradually increase over $120 \mathrm{~min}$ (second-phase insulin release) [25]. First-phase Stumvoll has been validated against this first-phase insulin release on hyperglycemic clamp test [26]. Although measurements of plasma insulin are ordinarily performed at $30 \mathrm{~min}$ on the OGTT, this time point may be too late to capture the early insulin response in some subjects with a prompt secretory response to glucose stimulation. In these subjects, the first burst of insulin secreted into the portal vein would suppress hepatic glucose production and decrease their plasma glucose equal to or below the fasting levels by $30 \mathrm{~min}$ after the glucose load.

The strength of our study is the longitudinal design, which allows for a comparison of future risk for diabetes among groups by insulinogenic index. However, several limitations of this study should be considered. First, the 


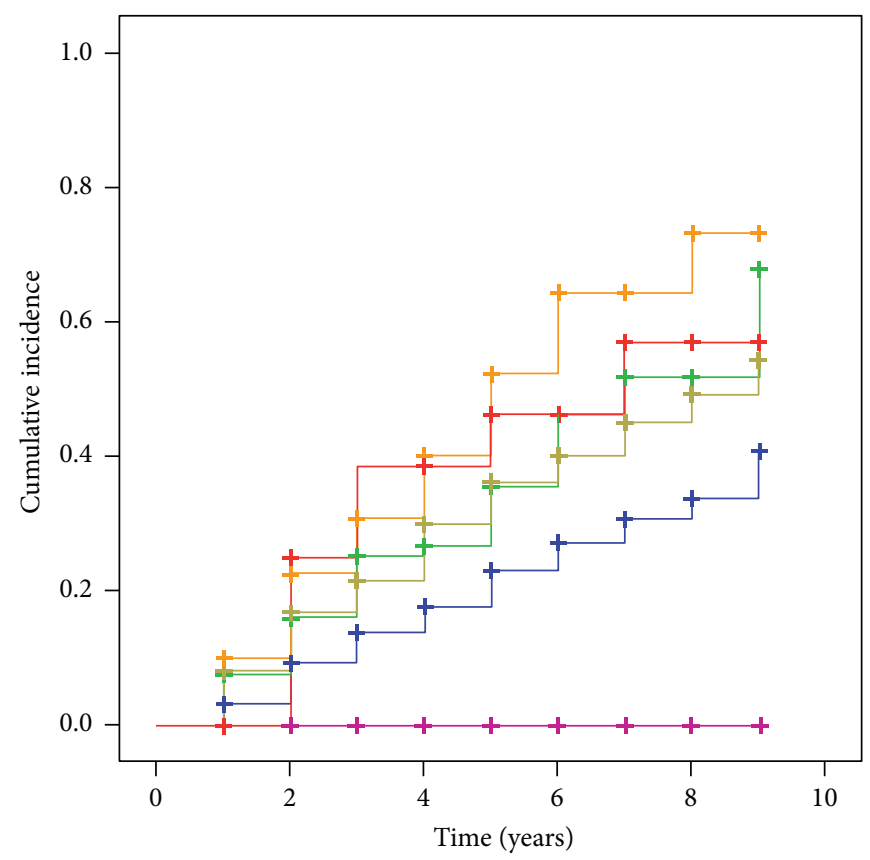

\begin{tabular}{|c|c|c|c|c|c|c|}
\hline & \multicolumn{4}{|c|}{ Positive insulinogenic index } & \multicolumn{2}{|c|}{ Nonpositive insulinogenic index } \\
\hline & \multicolumn{2}{|c|}{ NFG } & \multicolumn{2}{|c|}{ IFG } & \multirow{2}{*}{$\begin{array}{c}\Delta \mathrm{Glu}_{0-30} \leq 0 \\
(n=38)\end{array}$} & \multirow{2}{*}{$\begin{array}{c}\Delta \operatorname{Ins}_{0-30} \leq 0 \\
\quad(n=18)\end{array}$} \\
\hline & $\begin{array}{l}\text { Insulinogenic } \\
\quad \text { index } \\
\geq 0.4(n=441)\end{array}$ & $\begin{array}{c}\text { Insulinogenic } \\
\text { index } \\
<0.4(n=194)\end{array}$ & $\begin{array}{c}\text { Insulinogenic } \\
\text { index } \\
\geq 0.4(n=160)\end{array}$ & $\begin{array}{c}\text { Insulinogenic } \\
\text { index } \\
<0.4(n=131)\end{array}$ & & \\
\hline Incidence (\%) & $107(24.3)$ & $75(38.7)^{*}$ & $56(35.0)^{*}$ & $65(49.6)^{*}$ & $0(0.0)^{*}$ & $8(44.4)^{\#}$ \\
\hline $\begin{array}{l}\text { Mean follow-up time } \\
\text { (years) }\end{array}$ & 4.9 & 4.2 & 4.2 & 3.8 & 5.6 & 4.2 \\
\hline $\begin{array}{l}\text { Incidence rate } \\
\text { (per } 100 \text { person-years) }\end{array}$ & 5.0 & $9.2^{*}$ & $8.3^{*}$ & $13.1^{*}$ & $0.0^{*}$ & $10.6^{\#}$ \\
\hline
\end{tabular}

*Significantly different from NGT with insulinogenic index $\geq 0.4$ by log-rank test $(p<0.001)$. ${ }^{\#}$ Significantly different between $\Delta \mathrm{Glu}_{0-30} \leq 0$ and $\Delta \operatorname{Ins}_{0-30} \leq 0(p<0.001)$.

Figure 3: Cumulative incidence of impaired glucose tolerance or type 2 diabetes (2-hour PG $\geq 140 \mathrm{mg} / \mathrm{dL}$ ) by the Kaplan-Meier method among groups by insulinogenic index.

follow-up rate of the subjects was $67.7 \%$. Subjects who missed checkups during the follow-up period might be less conscious about their health, which biased the study subjects toward metabolically healthy people. However, baseline characteristics including BMI, glucose, and insulin concentrations between the subjects who were and were not followed were not significantly different. Second, measurements of C-peptide were not performed. C-peptide has been utilized to assess the insulin secretory function of beta cells because it is not degraded by the liver and thus represents prehepatic insulin secretion [27]. However, in estimation of the prehepatic insulin secretion, the calculation from insulin and that from $C$-peptide has been shown to be highly correlated $\left(R^{2}=0.75, p<0.001\right)$ [28]. Third, the measurement of plasma glucose concentrations relied on a single OGTT, which is known to have withinsubject variability [29].
In conclusion, a nonpositive insulinogenic index occurs at a given frequency in Japanese populations, due to a nonpositive glucose response or due to a nonpositive insulin response $30 \mathrm{~min}$ after the load. The former is efficient in disposing glucose and has a lower risk for future diabetes, while the latter showed a lower early insulin response and has a higher risk for future diabetes.

\section{Conflicts of Interest}

The authors declare that there are no conflicts of interest associated with this manuscript.

\section{Acknowledgments}

The authors thank the study participants and the staff at the Health Check Department of Hokuriku Central Hospital and 
Dr. Masaru Sakurai at Kanazawa Medical University for advice on the study design. This study was supported in part by Grants-in-Aid for Scientific Research from the Ministry of Education, Science, Sports, and Culture of Japan (17K09199).

\section{References}

[1] M. Hanefeld, C. Koehler, K. Fuecker et al., "Insulin secretion and insulin sensitivity pattern is different in isolated impaired glucose tolerance and impaired fasting glucose: the risk factor in impaired glucose tolerance for atherosclerosis and diabetes study," Diabetes Care, vol. 26, no. 3, pp. 868-874, 2003.

[2] Y. Nishi, M. Fukushima, H. Suzuki et al., "Insulin secretion and insulin sensitivity in Japanese subjects with impaired fasting glucose and isolated fasting hyperglycemia," Diabetes Research and Clinical Practice, vol. 70, no. 1, pp. 46-52, 2005.

[3] D. Tripathy, M. Carlsson, P. Almgren et al., "Insulin secretion and insulin sensitivity in relation to glucose tolerance: lessons from the Botnia study," Diabetes, vol. 49, no. 6, pp. 975-980, 2000.

[4] K. Kosaka, T. Kuzuya, H. Yoshinaga, and R. Hagura, "A prospective study of health check examinees for the development of non-insulin-dependent diabetes mellitus: relationship of the incidence of diabetes with the initial insulinogenic index and degree of obesity," Diabetic Medicine, vol. 13, no. 9, Supplement 6, pp. S120-S126, 1996.

[5] R. E. Pratley and C. Weyer, "The role of impaired early insulin secretion in the pathogenesis of type II diabetes mellitus," Diabetologia, vol. 44, no. 8, pp. 929-945, 2001.

[6] K. Kosaka, T. Kuzuya, R. Hagura, and H. Yoshinaga, "Insulin response to oral glucose load is consistently decreased in established non-insulin-dependent diabetes mellitus: the usefulness of decreased early insulin response as a predictor of insulindependent diabetes mellitus," Diabetic Medicine, vol. 13, no. 9, Supplement 6, pp. S109-S119, 1996.

[7] G. Pacini and A. Mari, "Methods for clinical assessment of insulin sensitivity and $\beta$-cell function," Best Practice \& Research Clinical Endocrinology \& Metabolism, vol. 17, no. 3, pp. 305-322, 2003.

[8] E. Cersosimo, C. Solis-Herrera, M. E. Trautmann, J. Malloy, and C. Triplitt, "Assessment of pancreatic $\beta$-cell function: review of methods and clinical applications," Current Diabetes Reviews, vol. 10, no. 1, pp. 2-42, 2014.

[9] D. R. Matthews, J. P. Hosker, A. S. Rudenski, B. A. Naylor, D. F. Treacher, and R. C. Turner, "Homeostasis model assessment: insulin resistance and $\beta$-cell function from fasting plasma glucose and insulin concentrations in man," Diabetologia, vol. 28, no. 7, pp. 412-419, 1985.

[10] L. J. C. J. den Biggelaar, S. J. S. Sep, S. J. P. M. Eussen et al., "Discriminatory ability of simple OGTT-based beta cell function indices for prediction of prediabetes and type 2 diabetes: the CODAM study," Diabetologia, vol. 60 , no. 3, pp. $432-$ 441, 2017.

[11] K. M. Utzschneider, R. L. Prigeon, M. V. Faulenbach et al., "Oral disposition index predicts the development of future diabetes above and beyond fasting and 2-h glucose levels," Diabetes Care, vol. 32, no. 2, pp. 335-341, 2009.

[12] M. A. Abdul-Ghani, K. Williams, R. A. DeFronzo, and M. Stern, "What is the best predictor of future type 2 diabetes?," Diabetes Care, vol. 30, no. 6, pp. 1544-1548, 2007.
[13] M. V. Faulenbach, L. A. Wright, C. Lorenzo et al., "Impact of differences in glucose tolerance on the prevalence of a negative insulinogenic index," Journal of Diabetes and Its Complications, vol. 27, no. 2, pp. 158-161, 2013.

[14] R. Oka, T. Aizawa, S. Miyamoto, T. Yoneda, and M. Yamagishi, "One-hour plasma glucose as a predictor of the development of type 2 diabetes in Japanese adults," Diabetic Medicine, vol. 33, no. 10, pp. 1399-1405, 2016.

[15] M. A. Abdul-Ghani, C. P. Jenkinson, D. K. Richardson, D. Tripathy, and R. A. DeFronzo, "Insulin secretion and action in subjects with impaired fasting glucose and impaired glucose tolerance: results from the Veterans Administration Genetic Epidemiology Study," Diabetes, vol. 55, no. 5, pp. 1430-1435, 2006.

[16] R. Oka, K. Yagi, M. Sakurai et al., "Insulin secretion and insulin sensitivity on the oral glucose tolerance test (OGTT) in middle-aged Japanese," Endocrine Journal, vol. 59, no. 1, pp. 55-64, 2012.

[17] M. Stumvoll, T. van Haeften, A. Fritsche, and J. Gerich, "Oral glucose tolerance test indexes for insulin sensitivity and secretion based on various availabilities of sampling times," Diabetes Care, vol. 24, no. 4, pp. 796-797, 2001.

[18] R. A. DeFronzo and M. Matsuda, "Reduced time points to calculate the composite index," Diabetes Care, vol. 33, no. 7, article e93, 2010.

[19] The Committee of the Japan Diabetes Society on the Diagnostic Criteria of Diabetes Mellitus, Y. Seino, K. Nanjo et al., "Report of the committee on the classification and diagnostic criteria of diabetes mellitus," Journal of Diabetes Investigation, vol. 1, no. 5, pp. 212-228, 2010.

[20] S. Genuth, K. G. Alberti, P. Bennett et al., "Follow-up report on the diagnosis of diabetes mellitus," Diabetes Care, vol. 26, no. 11, pp. 3160-3167, 2003.

[21] M. A. Abdul-Ghani, V. Lyssenko, T. Tuomi, R. A. DeFronzo, and L. Groop, "The shape of plasma glucose concentration curve during OGTT predicts future risk of type 2 diabetes," Diabetes/Metabolism Research and Reviews, vol. 26, no. 4, pp. 280-286, 2010.

[22] S. A. Metz, J. B. Halter, D. Porte Jr., and R. P. Robertson, "Suppression of plasma catecholamines and flushing by clonidine in man," The Journal of Clinical Endocrinology \& Metabolism, vol. 46, no. 1, pp. 83-90, 1978.

[23] C. Lorenzo, K. Williams, and S. M. Haffner, "Insulin secretion based on the late oral glucose tolerance test period and incident diabetes: the San Antonio Heart Study," Diabetic Medicine, vol. 29, no. 8, pp. e151-e158, 2012.

[24] D. L. Curry, L. L. Bennett, and G. M. Grodsky, "Dynamics of insulin secretion by the perfused rat pancreas," Endocrinology, vol. 83, no. 3, pp. 572-584, 1968.

[25] J. E. Gerich, "Is reduced first-phase insulin release the earliest detectable abnormality in individuals destined to develop type 2 diabetes?," Diabetes, vol. 51, Supplement 1, pp. S117-S121, 2002.

[26] M. Stumvoll, A. Mitrakou, W. Pimenta et al., "Use of the oral glucose tolerance test to assess insulin release and insulin sensitivity," Diabetes Care, vol. 23, no. 3, pp. 295-301, 2000.

[27] S. H. Kim and G. M. Reaven, "Insulin clearance: an underappreciated modulator of plasma insulin concentration," Journal of Investigative Medicine, vol. 64, no. 7, pp. 11621165, 2016 
[28] A. Tura, G. Pacini, A. Kautzky-Willer et al., "Estimation of prehepatic insulin secretion: comparison between standardized C-peptide and insulin kinetic models," Metabolism, vol. 61, no. 3, pp. 434-443, 2012.

[29] K. M. Utzschneider, R. L. Prigeon, J. Tong et al., "Withinsubject variability of measures of beta cell function derived from a 2 h OGTT: implications for research studies," Diabetologia, vol. 50, no. 12, pp. 2516-2525, 2007. 


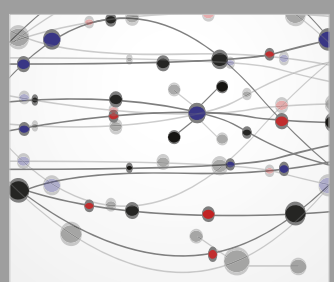

The Scientific World Journal
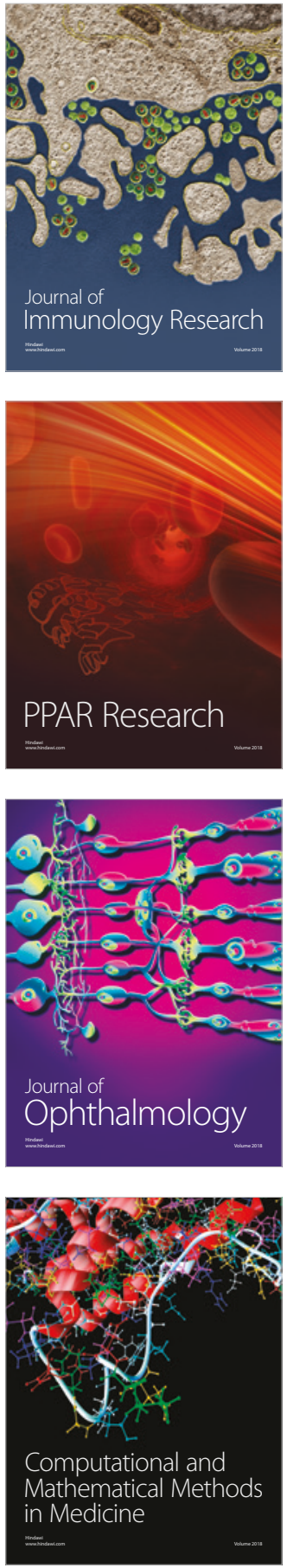

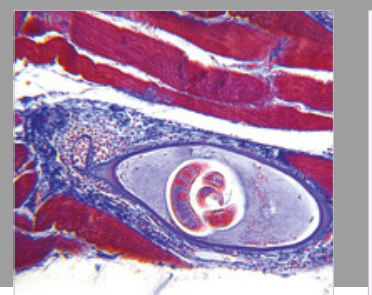

Gastroenterology Research and Practice

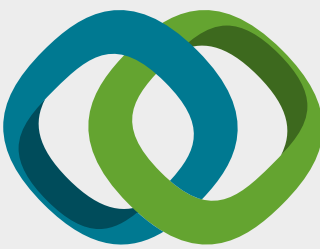

\section{Hindawi}

Submit your manuscripts at

www.hindawi.com
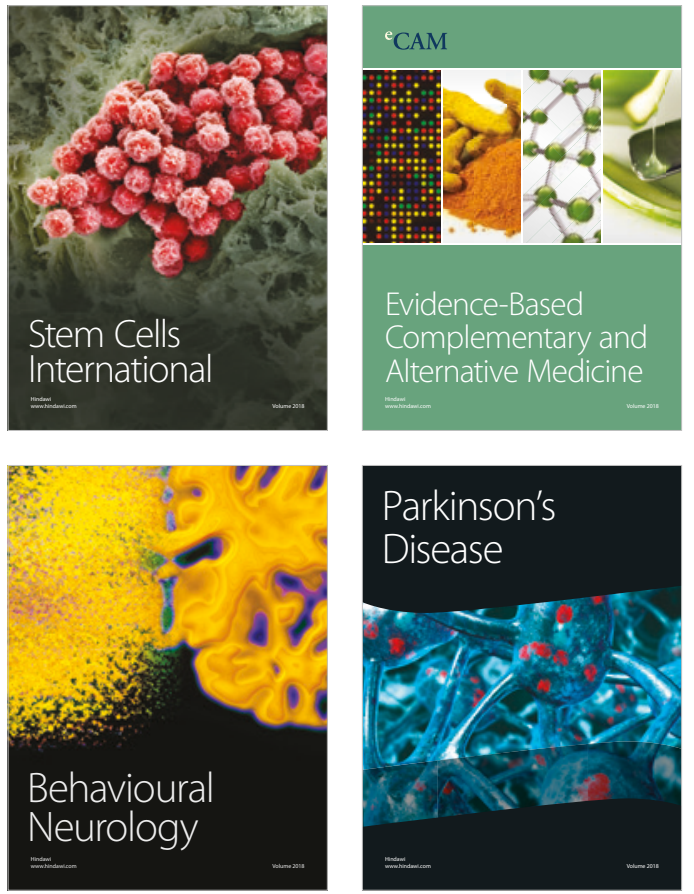

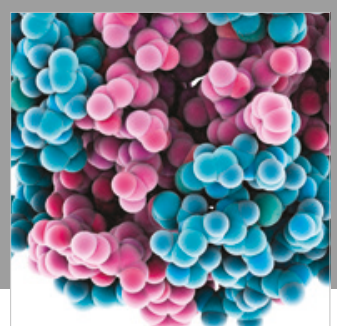

ournal of

Diabetes Research

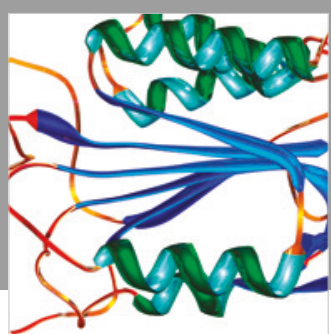

Disease Markers
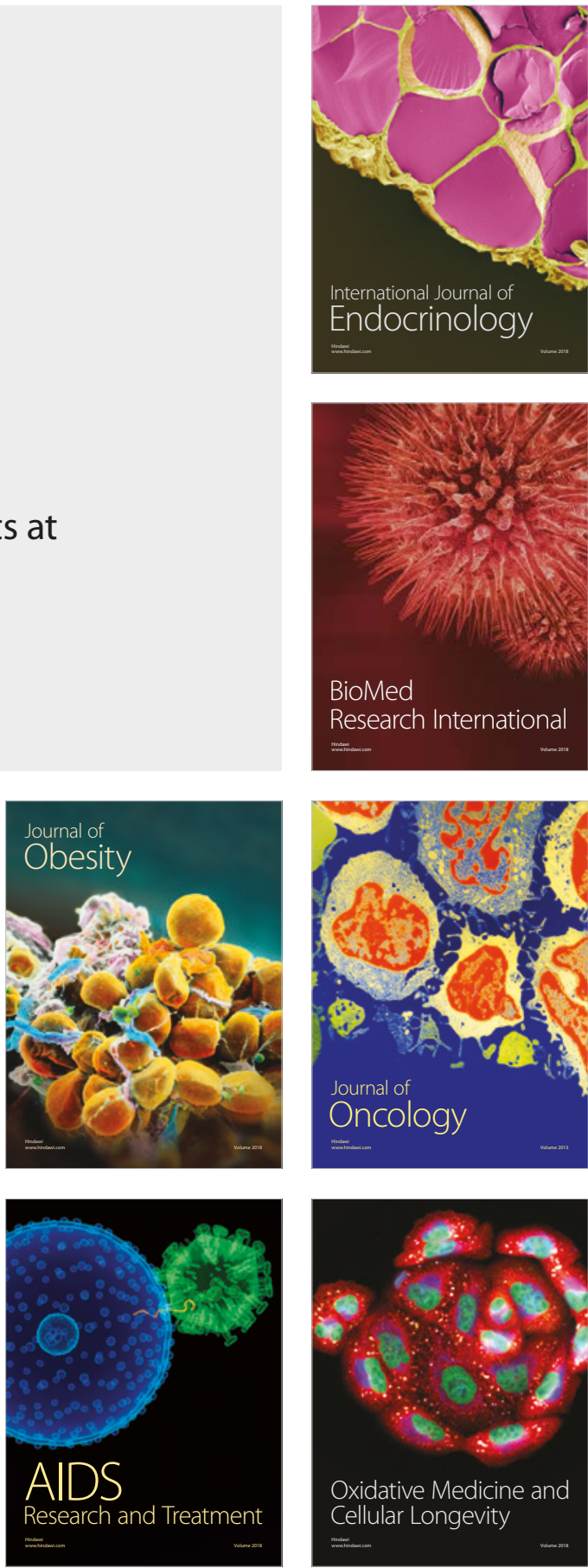